\title{
European Radiology: Thank you, goodbye and good luck!
}

\author{
Maximilian F. Reiser ${ }^{1}$
}

Received: 11 October 2017 / Accepted: 11 October 2017 /Published online: 26 October 2017

(C) European Society of Radiology 2017

With the end of my term as Editor-in-Chief of European Radiology it is time to say thank you and goodbye. Journals of high regard such as European Radiology are a real team effort and therefore, there are many people and institutions to whom I would like to express my sincere gratitude. In addition to those I was fortunate enough to get to know personally, there are many dear "electronic friends"- reviewers and authors - who made outstanding contributions to our journal.

European Radiology was founded by Prof. Dr. Dr. h.c. Josef Lissner, who was also my predecessor as Chairman of the Munich University Radiology Department. His successors as Editor-in-Chief were other giants of the European radiology endeavour, Prof. Dr. Albert L. Baert and Prof. Dr. Adrian K. Dixon. Under their capable leadership, European Radiology matured and became an internationally renowned journal, publishing high-quality articles submitted from all over the world.

Along with the implementation of two other journals of the European Society of Radiology (ESR) family, Insights into Imaging and European Radiology Experimental, the format of European Radiology was adapted and streamlined and is now devoted to the dissemination of cutting-edge research in the field of clinical radiology. Originality and innovation are key criteria for selecting articles to be published in European Radiology.

Since 2007, the number of original articles submitted to European Radiology has increased by a factor of 2.5. This impressive figure underlines the attractiveness of our journal.

Maximilian F. Reiser

Maximilian.Reiser@med.uni-muenchen.de

1 Department of Radiology, Ludwig-Maximilians-University Hospital, Munich, Germany
On the other hand, this also meant that the acceptance rate had to be reduced and only those manuscripts which achieved the highest priority could be considered for publication. Much to our regret, there were many good submissions we could not accept. The rise in submissions inevitably resulted in an everincreasing workload, competently managed by the whole team.

I had the privilege to work with the tireless and highly professional staff of the Editorial Office in Vienna headed by Stefanie Bolldorf. In Munich, Dr. Katrin Deininger, who manages the review process and liaises with the office in Vienna, provided invaluable contributions to the journal. Working closely with her was inspiring and efficient. Our publisher Nature Springer has been supporting our journal since the onset and I highly appreciated the collegial cooperation with Dr. Ute Heilmann and Dr. Isabel Arnold.

I would also like to express my sincere gratitude to the Deputy Editors of European Radiology, Prof. Rahel KubikHuch, Prof. José María García Santos, Dr. Sujal Desai and Prof. Peter Vock, whose contributions and hard work as well as their expert advice in shaping the strategy for the further development of the journal cannot be overemphasised. Together with the members of the Scientific Editorial Board, the Deputy Editors provide the subspecialised expertise in their fields, which allows for adequate assessment of the scientific value and originality of submitted manuscripts.

For a scientific journal it is mandatory to maintain and safeguard the validity and ethical standards of the publications. The work of the reviewers is key to achieving this goal. The reviewers invest an enormous amount of their spare time engaging in this task and I cannot thank them enough for their tremendous dedication and support.

The ESR permitted me to engage professional specialists in bioinformatics, who check manuscripts for their methodological correctness and statistical rigour and provide advice to the authors on how to improve, if required. 
For the radiological community it is of high importance to develop the knowledge and skills of the younger generation in scientific publishing. Therefore, the Albert L. Baert Editorial Fellowship was introduced four years ago, which allows gifted young imaging scientists to make themselves familiar with the principles of manuscript evaluation, manuscript editing, organisation of peer review, manuscript production and publishing, including electronic publication. As of now, we have hosted four fellows in Munich and we are happy to report that this was a highly rewarding experience for both the fellows and ourselves.

The ESR has continuously and effectively supported and encouraged its flagship journal European Radiology for which I would like to express my gratitude. The Chairpersons of the ESR Publication Committee, Prof. Dr. Paul M. Parizel, Prof. Dr. Lorenzo Derchi and Prof. Dr. Regina G. H. Beets-Tan, made many important suggestions and were always open for our problems and requests.

Among various excellent applicants for the position of Editor-in-Chief of European Radiology, the ESR Search Committee selected Prof. Dr. Yves Menu from Paris. He has an outstanding scientific profile, extensive editorial experience, distinctive communication abilities and has served in prominent positions of ESR. I am sure that he will introduce exciting and forward-looking innovations and ideas, and that he will manage the journal most effectively so that European Radiology will flourish and grow under his leadership. Together with the two other journals in our family, Insights into Imaging and European Radiology Experimental, and their respective Editors-in-Chief, Prof. Dr. Luis MartíBonmatí and Prof. Dr. Francesco Sardanelli, the ESR and the European radiology community are excellently prepared for the future. The readers of these journals can look forward to stimulating and enthralling content.

Funding The authors state that this work has not received any funding.

\section{Compliance with ethical standards}

Guarantor The scientific guarantor of this publication is Maximilian F. Reiser.

Conflict of interest The authors of this manuscript declare no relationships with any companies whose products or services may be related to the subject matter of the article.

Statistics and biometry No complex statistical methods were necessary for this paper.

Informed consent Written informed consent was not required for this study because this is an editorial without any study subjects.

Ethical approval Institutional review board approval was not required because this is an editorial without any study subjects.

Methodology N/A 